\title{
Substitution of Wheat Flour by Local Cereals and Pulses Flour "An Approach to Overcome Wheat Gap in Egypt" 2. Gluten Content and Falling Number Zeinab R. Atia ${ }^{1}$,M.M El-Genbeihy ${ }^{2}$ and M.Abd El- Sattar Ahmed ${ }^{2 *}$ \\ 1 lecturer, Crop Science Dept., Fac.Agric. (El-Shatby), Alexandria university . \\ 2 Professor, Crop Science Dept., Fac.Agric. (El-Shatby), Alexandria university . \\ * corresponding author (Mohamed.A@alexu.edu.eg).
}

ABSTRACT

Wheat blends with rice flour in comparison to blends with barley flour, indicated a reduction in dry gluten percentage reached $-0.027(\mathrm{p} \geq 0.561),-0.332(\mathrm{p} \geq 0.008)$ and $-0.227(\mathrm{p} \geq 0.0001)$ for wheat cultivars Misr2, Giza171 and Gimmeza11, respectively. A blend contained substitution with 5\% fenugreek flour and 5\% soybean flour contained significantly less $0.078,0.251$ and $0.084 \%$ dry gluten in comparison to blends that contained a substitution of 5\% fenugreek for cultivars, Misr2, Giza171 and Gimmeza11, respectively. Also, the comparison between the group of blends that contained fenugreek and soybean flours versus those contained soybean flour revealed significant reduction in dry gluten percentage due to the substitution by two pulse flour rather than soybean flour reached -0.078 , 0.0172 and $-0.111 \%$ for Misr2, Giza171 and Gimmeza11 cultivars, respectively.

Substitution of wheat flour by rice flour in blends resulted in significant decrease in dry gluten percentage of Misr 2 cultivar reached $0.056 \%$ over blends with sorghum flour. While, blends of Giza171 had significantly $0.233 \%$ higher dry gluten. Also, rice/Gimmeza11 flour blends showed insignificantly $0.010 \%$ higher dry gluten percentage relative to blends with sorghum flour.

Wheat flour blends contained sorghum flour replacement gave higher figures of falling number reached 16.14, 14.63 and10.33 in comparison to the corresponding blends with rice flour replacement for wheat flours of Misr2, Giza171 and Gimmeza11, respectively. Also Misr2 blends with rice flour gave lower falling number over blends with barley flour $(6.522 \mathrm{Sec})$. While, Giza171 blends with rice flour had higher values of falling number in comparison to those blends with barley flour while, Gimmeza11 blends with rice flour had 7.07 Sec. rise in falling number in comparison to blends with barley flour.

Keywords: Substitution, wheat flour, rice flour, sorghum flour, pulses flour, gluten, falling number.

\section{INTRODUCTION}

Wheat' Triticum spp' is one of the oldest demosticated crops. Its use as food goes back to 8000 years. Sine, it represented the stable food for early civilizations in Europe, West Asia and North Africa. The area devoted to wheat cultivation is greater than any commercial crop with world trade greater all other crops combined (Qarooniet al., 1987).

Dough produced from wheat flour different from those made from other cereals in their viscoelastic properties. The raised bread loaf is possible because the wheat kernel contain gluten, an elastic form of protein that trap minute bubbles of carbon dioxide when fermentation occurs in leavened dough causing the dough to rise (Popa et al., 2014).The insoluble protein from in wheat flour when come to contact with water, shows the viscoelastic mass of gluten, which represents about 78 to 85 percent of total wheat endosperm protein. This type of protein is complex composed of polymeric and monomeric proteins known as glutenins and gliadins. Glutenins confer elasticity, while, gliadins confer mainly viscous flow and extensibility. This is how gluten is responsible for vescoelastic properties of wheat- flour dough. It is also the main character dictating the proper use of wheat variety. Gluten viscoelasticity for end -use purposes is commonly known as flour or dough strength. (Qarooni et al., 1987). Roughly, wheat flour contains the same amounts of glutenins and gliadins the unbalance of glutein/gliadin ratio may change the vescoelastic properties. The fraction of gluten is, however, the major protein factor responsible for variation in dough strength among wheat varieties (Rozylo and Laskowski, 2011).

In Egypt, bread is traditionally produced from wheat 'triticumaestivum' flour. Due to high demand, about 50\% of needed wheat is imported. Using alternate flour in bread making was introduced many years ago. Many of tested wheat blends showed levels of success in bread making. Local non wheat flours were used in replacing portions of wheat flour in bread making worldwide(Bhatt and Gupta, 2005).

Alternative non wheat cereals that has capacity to substitute wheat in bread flour in Egypt, includes barley, maize, rice and sorghum.

Legumes flours are blended with wheat flour at variable ratios to increase water absorption and reducing dough stability.Composite flour technology entails reaching high quality products at an economic level. This might be attained by mixing defatted soy flour (Minarro et al., 2012and Elisa et al 2017) or lupine flour (Hull and Johnson, 2004).

The recent study was carried out to determine the possibility of substituting local wheat varieties 
flour with naked rice, sorghum and barley flours along with the optimum mixing ratio for local pulses represented by Fenugreek flour and soy bean flours in relation to gluten content and falling number .

\section{MATERIALS AND METHODS}

The recent study included studying the possibility of substituting local cereals flours (rice, sorghum and naked barley) to local bread wheat cultivars. Adding fenugreek local pulse flour and imported soybean flour to improve characters of gluten. The studied local bread wheat cultivars were ; Misr 2,Giza 171 and and pulse flour addition

\begin{tabular}{|c|c|c|c|c|}
\hline \multirow{2}{*}{ Code } & \multirow{2}{*}{ Treatment } & \multicolumn{3}{|c|}{ Component of one kilogram blended flour } \\
\hline & & wheat & cereal & pulse \\
\hline 1 & WF $100 \%$ & 1000 & - & - \\
\hline 2 & $\mathrm{WF}+10 \% \mathrm{RF}$ & 900 & 100 & - \\
\hline 3 & $\mathrm{WF}+10 \% \mathrm{RF}+5 \% \mathrm{Fen}$ & 850 & 100 & 50 \\
\hline 4 & $\mathrm{WF}+10 \% \mathrm{RF}+5 \%$ So & 850 & 100 & 50 \\
\hline 5 & $\mathrm{WF}+20 \% \mathrm{RF}$ & 800 & 200 & - \\
\hline 6 & $\mathrm{WF}+20 \% \mathrm{RF}+5 \% \mathrm{Fen}$ & 750 & 200 & 50 \\
\hline 7 & $\mathrm{WF}+20 \% \mathrm{RF}+5 \%$ So & 750 & 200 & 50 \\
\hline 8 & $\mathrm{WF}+30 \% \mathrm{RF}$ & 700 & 300 & - \\
\hline 9 & $\mathrm{WF}+30 \% \mathrm{RF}+5 \% \mathrm{Fen}$ & 650 & 300 & 50 \\
\hline 10 & $\mathrm{WF}+30 \% \mathrm{RF}+5 \%$ So & 650 & 300 & 50 \\
\hline 11 & $\mathrm{WF}+10 \% \mathrm{SF}$ & 900 & 100 & - \\
\hline 12 & $\mathrm{WF}+10 \% \mathrm{SF}+5 \% \mathrm{Fen}$ & 850 & 100 & 50 \\
\hline 13 & $\mathrm{WF}+10 \% \mathrm{Sf}+5 \%$ So & 850 & 100 & 50 \\
\hline 14 & $\mathrm{WF}+20 \% \mathrm{SF}$ & 800 & 200 & - \\
\hline 15 & $\mathrm{WF}+20 \% \mathrm{SF}+5 \% \mathrm{Fen}$ & 750 & 200 & 50 \\
\hline 16 & $\mathrm{WF}+20 \% \mathrm{SF}+5 \%$ So & 750 & 200 & 50 \\
\hline 17 & $\mathrm{WF}+30 \% \mathrm{SF}$ & 700 & 300 & - \\
\hline 18 & $\mathrm{WF}+30 \% \mathrm{SF}+5 \% \mathrm{Fen}$ & 650 & 300 & 50 \\
\hline 19 & $\mathrm{WF}+30 \% \mathrm{SF}+5 \%$ So & 650 & 300 & 50 \\
\hline 20 & $\mathrm{WF}+10 \% \mathrm{BF}$ & 900 & 100 & - \\
\hline 21 & $\mathrm{WF}+10 \% \mathrm{BF}+5 \% \mathrm{Fen}$ & 850 & 100 & 50 \\
\hline 22 & $\mathrm{WF}+10 \% \mathrm{BF}+5 \%$ So & 850 & 100 & 50 \\
\hline 23 & $\mathrm{WF}+20 \% \mathrm{BF}$ & 800 & 200 & - \\
\hline 24 & $\mathrm{WF}+20 \% \mathrm{BF}+5 \%$ Fen & 750 & 200 & 50 \\
\hline 25 & $\mathrm{WF}+20 \% \mathrm{BF}+5 \%$ So & 750 & 200 & 50 \\
\hline 26 & $\mathrm{WF}+30 \% \mathrm{BF}$ & 700 & 300 & - \\
\hline 27 & $\mathrm{WF}+30 \% \mathrm{BF}+5 \% \mathrm{Fen}$ & 650 & 300 & 50 \\
\hline 28 & $\mathrm{WF}+30 \% \mathrm{BF}+5 \%$ So & 650 & 300 & 50 \\
\hline 29 & $\mathrm{WF}+5 \% \mathrm{Fen}$ & 950 & - & 50 \\
\hline 30 & $\mathrm{WF}+5 \%$ So & 950 & - & 50 \\
\hline 31 & $\mathrm{WF}+5 \% \mathrm{Fen}+5 \%$ So & 900 & - & 100 \\
\hline
\end{tabular}

WF; Wheat flour

SF; Sorghum flour

Fen; Fenugreek flour
Gemmiza 11. Separate experiments were carried out for each bread wheat variety.

Raw materials for local cereals, fenugreek and bread wheat cultivars were obtained from Agricultural Research center. Ministry of Agriculture, Giza, Egypt. 86\% extraction flour were prepared by following AACC; 26-10 A method .Tempered cleaned grains milled by barabender quadrumat mill using the barabender procedure. For each local bread wheat cultivar the following flour blends were prepared (Table1).

Table (1: list of studied flour blends that represent different levels of local cereals flour substitution 
The studied flour blends were subject to the following determination:

Gluten content:According to AACC 38-12.02, 2000 asfollows: Flour samples were subjected to an automatic gluten washing apparatus (Glutomatic;perten-type 2200-serial no. 015126) and centrifuged on an especially constructed sieve under standardized conditions was used. The weight of wet gluten Forced through the sieve and the total weight of wet gluten (passed through and remaining of the sieve) areweighed. The total wet gluten was then dried under standardized conditions and weighed. Total wet gluten and total dry gluten contents were expressed as percentages of the sample.

Falling number; According to AACC 56$81.03,1999$ as follows: This method is based on the ability of amylase to liquefy a starch gel .The activity of the enzyme is measured by falling number, defined as time in seconds required stirring and allowing stirrer to fall a measured distance through a hot aqueous flour or meal gel undergoing liquefaction. $\alpha$ amylase activity is associated with kernel sprouting, andboth are inversely correlated with falling number. Falling number apparatus (perten-type1500-serial no. 077155), including standardized precision viscometer tubes with close tolerances, inside diameter $\pm 0.02 \mathrm{~mm}$, outside $\pm 0.3 \mathrm{~mm}$ and athermometer (National Bureau of standards or equivalent), calibrated in $0.1^{\circ} \mathrm{C}$, and certified accurate to $\pm 0.3^{\circ} \mathrm{C}$.

\section{RESULTS AND DISCUSSION}

The main objective of the recent study was to assess the possibility of substituting local cereals flours represented by rice, sorghum and naked barley to wheat flour. Three separate experiments were carried out each included one of the local bread wheat varieties. These were Misr2, Giza171 and Gimmiza11. Combined analysis of experiments (cultivars) was performed. Since, the assumption of homogeneity of variances were not rejected. The obtained results were presented for gluten content and falling number:

Table 2 illustrated the analysis of variance for wet gluten, dry gluten and falling number of flour blends as affected by various levels of local cereals and pulse flour substitution. The three studied wheat cultivars gave significantly similar rheological characters. Whereas, blends of flour and the interaction between cultivars and blends were significant $(\mathrm{p} \geq 0.01)$.

Table 2: Mean squares of flour rheological characters (dry gluten, wet gluten and falling number ) as affected by wheat cultivar and flour blends.

\begin{tabular}{|l|l|l|l|}
\hline \multirow{2}{*}{ S.O.V. } & \multirow{2}{*}{ d.f. } & \multicolumn{1}{c|}{ M.S } \\
\cline { 3 - 4 } & & \multicolumn{1}{c|}{ Dry gluten } & \multicolumn{1}{c|}{ Falling number } \\
\hline Cultivar (A) & 2 & $85.411^{\text {n.s }}$ & $23556.511^{\text {n.s }}$ \\
\hline Error & 4 & 3.671 & 171.664 \\
\hline Treatments (B) & 30 & $5.573^{* *}$ & $5038.224^{* *}$ \\
\hline $\mathrm{A}^{*} \mathrm{~B}$ & 60 & $0.836^{* *}$ & 462.683 \\
\hline Error & 180 & 0.290 & 54.642 \\
\hline
\end{tabular}

**, indicate significance at 0.01 level.

n.s., not significantly different

\section{Dry gluten:}

Dry gluten content of different studied flour blends as affected by rice flour substitution were presented in Table 3. Over the studied wheat cultivars, gluten content of the different flour blends was significantly lower than the recorded value for wheat flour $(8.111 \%)$ substitution with $10 \%$ rice flour gave significantly lower gluten percentage (7.493\%). Additional substitution with any of fenugreek or soybean flour, although, showed lower dry gluten percentage, that reduction had not reached the level of significance (7.20) and $7.339 \%$ for $10 \%$ rice flour+5\% fenugreek flour and $10 \%$ rice flour $+5 \%$ soybean flour substitution, respectively). Rising the level of rice flour substitution to 20 or $30 \%$ gave significantly and similar lower dry gluten percentage of flour blends (6.210 and $6.459 \%$ for each of 20 and $30 \%$ rice flour substitution blends, respectively). Also, further substitution by $5 \%$ fenugreek flour gave similarly lower dry gluten percentage, irrespective of the level of rice flour substitution $(5.760$ and $5.810 \%$ for $20 \%$ rice flour $+5 \%$ fenugreek flour and $30 \%$ rice flour $+5 \%$ fenugreek flour substitution, respectively). Soybean flour substitution to rice flour + wheat flour blends gave insignificant increase in dry gluten percentage (6.026 and 5.789 $\%$ for $20 \%$ rice flour $+5 \%$ soybean flour and $30 \%$ rice flour $+5 \%$ soybean flour blends with wheat flour, respectively).

As for the interaction between blends and wheat cultivars, Giza171 cultivar flour scored a 
high magnitude figures of dry gluten, although, that superiority had not reached the level of significance $(8.467,8.367$ and $7.500 \%$ for Giza171, Gimmeza11 and Misr2, respectively). That trend was observed for all studied wheat flour/ rice flour blends. In the meantime, dry gluten values presented by Misr2 wheat cultivar/rice flour blends were of lower magnitude. The highest dry gluten value was that of $10 \%$ rice flour $+5 \%$ soybean of Giza171 wheat cultivar's flour substitution $(8.483 \%)$. whereas, the least value was presented by Misr 2 wheat flour substitution with $30 \%$ rice flour $+5 \%$ soybean flour $(4.700 \%)$.

Table 3; Effect of rice flour and pulses flour substitution on dry gluten of flour blends of wheat cultivars

\begin{tabular}{|l|c|c|c|c|}
\hline \multirow{2}{*}{ Flour blends } & \multicolumn{4}{c|}{ Wheat cultivar } \\
\cline { 2 - 5 } & Misr2 & Giza171 & Gimmeza11 & Combined \\
\hline WF 100\% & 7.500 & 8.467 & 8.367 & 8.111 \\
\hline WF+ 10\% RF & 7.333 & 7.880 & 7.267 & 7.493 \\
\hline WF+10\% RF+ 5\% Fen & 6.333 & 8.103 & 7.167 & 7.201 \\
\hline WF+10\% RF+ 5\% Soy & 6.400 & 8.483 & 7.133 & 7.339 \\
\hline WF+ 20\% RF & 5.600 & 6.420 & 6.610 & 6.210 \\
\hline WF+ 20\% RF+ 5\% Fen & 5.433 & 6.023 & 5.823 & 5.760 \\
\hline WF+ 20\% RF+ 5\% Soy & 5.267 & 7.090 & 5.720 & 6.026 \\
\hline WF+ 30\% RF & 5.400 & 6.910 & 7.067 & 6.459 \\
\hline WF+ 30\% RF+ 5\% Fen & 5.067 & 6.863 & 5.500 & 5.810 \\
\hline WF+ 30\% RF+ 5\% Soy & 4.700 & 7.233 & 5.433 & 5.789 \\
\hline
\end{tabular}

WF; Wheat Flour RF; Rice flour Fen; Fenugreek Flour Soy; Soybean flour L.S.D. ${ }_{0.01}$ flour blends; 0.5077

L.S.D. 0.01 flour blend $\times$ cultivar; 0.8794

Table 4 reflected the effect of different levels of rice flour substitution to wheat flour on dry gluten percentage through orthogonal comparisons. Overall wheat cultivars and pulse flour substitution, $10 \%$ rice flour substitution showed significantly higher $(\mathrm{p} \geq 0.0001)$ dry gluten percentage over $20 \%$ substitution $(0.628,0.822$ and $0.569 \%$ for blends with Misr2, Giza171 and Gimmeza11 wheat cultivars, respectively). In the meantime, flour blends of Misr2 cultivar had 20\% rice flour had $0.189 \%$ higher dry gluten percentage $(\mathrm{p} \geq 0.0001)$. Also, those of Giza171 and Gimmeza11 blends had insignificantly lower $(-0.264 \%)$ and higher $(+0.026 \%)$ dry gluten percentage, respectively.

Table 4: Orthogonal comparisons between different levels of rice flour substitution to wheat flour reflected on dry gluten of the flour blend

\begin{tabular}{|c|c|c|c|c|c|c|}
\hline \multirow{3}{*}{ Comparisons } & \multicolumn{6}{|c|}{ Wheat cultivar } \\
\hline & \multicolumn{2}{|c|}{ Misr2 } & \multicolumn{2}{|c|}{ Giza171 } & \multicolumn{2}{|c|}{ Gimmeza11 } \\
\hline & Effect & Significance & Effect & Significance & Effect & Significance \\
\hline $\begin{array}{l}\mathrm{WF}+10 \% \mathrm{RF} v \cdot s \\
\mathrm{WF}+20 \% \mathrm{RF}\end{array}$ & 0.628 & 0.000 & 0.822 & 0.000 & 0.569 & 0.000 \\
\hline $\begin{array}{l}\mathrm{WF}+20 \% \mathrm{RF} v . s \\
\mathrm{WF}+30 \% \mathrm{RF}\end{array}$ & 0.189 & 0.004 & -0.246 & 0.244 & 0.026 & 0.690 \\
\hline
\end{tabular}

WF; Wheat Flour, RF; Rice Flour,Fen; Fenugreek Flour, Soy; Soybean flour 
Over the studied wheat cultivars, substitution of sorghum flour gave significantly lower dry gluten percentage (Table 5). 10\% sorghum flour substitution to wheat flour whether alone or with additional substitution by any of 5\% fenugreek or sorghum flours scored significantly similar dry gluten percentage $(7.338,7.216$ and $7.458 \%$ for blends of $10 \%$ sorghum flour, $10 \%$ sorghum flour $+5 \%$ fenugreek flour and $10 \%$ sorghum flour $+5 \%$ soybean flour, respectively). Increasing the level of sorghum flour substitution to 20 or $30 \%$ gave significantly lower and similar dry gluten percentages (about $6.00 \%$ ).

Table 5: Effect of Sorghum flour and pulses Flour substitution on dry gluten of flour blends of wheat cultivars.

\begin{tabular}{|l|c|c|c|c|}
\hline \multirow{2}{*}{ Flour blends } & \multicolumn{3}{|c|}{ Wheat cultivar } \\
\cline { 2 - 5 } & Misr2 & Giza171 & Gimmeza11 & Combined \\
\hline WF 100\% & 7.500 & 8.467 & 8.367 & 8.111 \\
\hline WF+ 10\% SF & 6.467 & 8.047 & 7.500 & 7.338 \\
\hline WF+10\% SF+ 5\% Fen & 6.300 & 8.147 & 7.200 & 7.216 \\
\hline WF+10\% SF+ 5\% Soy & 6.400 & 8.707 & 7.267 & 7.458 \\
\hline WF+ 20\% SF & 5.233 & 6.370 & 6.287 & 5.963 \\
\hline WF+ 20\% SF+ 5\% Fen & 5.167 & 7.480 & 5.943 & 6.197 \\
\hline WF+ 20\% SF+ 5\% Soy & 5.200 & 8.617 & 5.943 & 6.587 \\
\hline WF+ 30\% SF & 5.400 & 6.637 & 6.200 & 6.079 \\
\hline WF+ 30\% SF+ 5\% Fen & 5.217 & 7.223 & 5.803 & 6.081 \\
\hline WF+ 30\% SF+ 5\% Soy & 5.150 & 7.970 & 5.757 & 6.292 \\
\hline
\end{tabular}

WF; Wheat Flour SF; Sorghum Flour

L.S.D. blends ${ }_{0.01} ; 0.5077$

L.S.D. blends $\times$ cultivar $_{0.01} ; 0.8794$

To clarify the role of sorghum flour substitution to wheat flour over the different blends, orthogonal comparisons (Table 6) showed that, $10 \%$ sorghum flour substitution had higher levels of dry gluten relative to blends had $20 \%$ sorghum flours (0.594, 0.406 and $0.632 \%(p \geq 0.0001)$ for blends of Misr2, Giza171 and Gimmeza11 wheat cultivars respectively). Also, Misr2 flour blends that contained $20 \%$ sorghum flour had insignificantly low-
Regarding wheat cultivars $\times$ blends interaction Giza171 wheat blends, showed dry gluten Misr2 wheat blends, showed relatively lower dry gluten percentages. The highest dry gluten values were presented by any of Giza171 wheat flour or the blend of $20 \%$ sorghum flour $+5 \%$ soybean flour (8.467 and $8.617 \%$ respectively). Whereas, the least figures were shown by flour blends of Misr2 wheat cultivar that contained 20 or $30 \%$ sorghum flour alone or with $5 \%$ pulse flours (about $5.00 \%$ ). percentages of relatively higher magnitude, while

Table 6: Orthogonal comparisons between different levels of sorghum flour supplementation to wheat flour reflected on dry gluten percentage of flour blend.

\begin{tabular}{|c|c|c|c|c|c|c|}
\hline \multirow{3}{*}{ Comparisons } & \multicolumn{6}{|c|}{ Wheat cultivar } \\
\hline & \multicolumn{2}{|c|}{ Misr2 } & \multicolumn{2}{|c|}{ Giza171 } & \multicolumn{2}{|c|}{ Gimmeza11 } \\
\hline & Effect & Significance & Effect & Significance & Effect & Significance \\
\hline $\begin{array}{l}\mathrm{WF}+10 \% \mathrm{SF} v . s \\
\mathrm{WF}+20 \% \mathrm{SF}\end{array}$ & 0.594 & 0.000 & 0.406 & 0.056 & 0.632 & 0.000 \\
\hline $\begin{array}{l}\mathrm{WF}+20 \% \mathrm{SF} v . s \\
\mathrm{WF}+30 \% \mathrm{SF}\end{array}$ & -0.028 & 0.195 & 0.106 & 0.259 & 0.069 & 0.029 \\
\hline
\end{tabular}

WF; Wheat Flour SF; Sorghum FlourFen; Fenugreek FlourSoy; Soybean flour 


\section{Barley flour substitution:}

Table 7 showed the effect of barley flour and pulses flour substitution on dry gluten of flour blends. As an average over the three studied wheat cultivars, barley flour substitution was associated with significant reduction of flour dry gluten percentage, irrespective of the level of barley flour substitution (10 or 20 or $30 \%$ ). Wheat flour contained $8.111 \%$ dry gluten, whereas, flour blend contained $10 \%$ barley flour contained significantly similar dry gluten percentage of 7.530, 7.191 and $7.502 \%$ dry gluten for wheat/barley, wheat/barley $+5 \%$ fenugreek flour and wheat/ barley $+5 \%$ soybean flour, respectively. Significantly lower dry gluten percentage were associated with increasing the level of barley flour substitution to $20 \%$. Within the $20 \%$ barley flour blends, the highest magnitude of dry gluten with that of wheat flour $+20 \%$ barley flour $+5 \%$ soybean flour blend $(6.588 \%)$. A relatively insignificant rice in dry gluten percentage were marked with $30 \%$ barley flour blends being highest for wheat flour $+30 \%$ barley flour + $5 \%$ fenugreek flour $(7.158 \%)$.

The significant interaction between the studied wheat cultivar flour and the different blends was illustrated when considering the magnitude of dry gluten figures for different cultivars, since, Giza171 wheat cultivar showed relatively higher figures. In the meantime, the highest dry gluten percentages were provided by Giza171 wheat flour $+10 \%$ barley flour $+5 \%$ soybean flour $(8.943 \%)$. In a time that the least figure was provided by any Misr2 wheat flour +20 or $30 \%$ barley flour $+5 \%$ any of fenugreek or soybean flour (about 5.4\%). In Misr2 flour blends, blends of various levels of barley flour substitution were significantly inferior to full wheat flour. While, all the studied Giza171 flour blends recorded variable insignificant increase in dry gluten percentage, except for, blends of $20 \%$ barley flour and $20 \%$ barley flour $+5 \%$ fenugreek flour that contained significantly lower dry gluten percentage $(6.643$ and $6.227 \%$, respectively).

Table 7: Effect of barley flour and pulses flour substitution on dry gluten of flour blends of wheat cultivars

\begin{tabular}{|l|c|c|c|c|}
\hline \multirow{2}{*}{ Flour blends } & \multicolumn{4}{c|}{ Wheat cultivar } \\
\cline { 2 - 5 } & Misr2 & Giza171 & Gimmeza11 & Combined \\
\hline WF 100\% & 7.500 & 8.467 & 8.367 & 8.111 \\
\hline WF+ 10\% BF & 6.517 & 8.270 & 7.803 & 7.530 \\
\hline WF+10\% BF+ 5\% Fen & 6.417 & 7.770 & 7.387 & 7.191 \\
\hline WF+10\% BF+ 5\% Soy & 6.193 & 8.943 & 7.370 & 7.502 \\
\hline WF+ 20\% BF & 5.400 & 6.643 & 6.333 & 6.126 \\
\hline WF+ 20\% BF+ 5\% Fen & 5.133 & 6.227 & 6.900 & 6.087 \\
\hline WF+ 20\% BF+ 5\% Soy & 5.633 & 8.103 & 6.027 & 6.588 \\
\hline WF+ 30\% BF & 5.843 & 8.227 & 6.167 & 6.746 \\
\hline WF+ 30\% BF+ 5\% Fen & 5.400 & 8.223 & 7.850 & 7.158 \\
\hline WF+ 30\% BF+ 5\% Soy & 5.487 & 8.583 & 5.963 & 6.678 \\
\hline
\end{tabular}

WF; Wheat Flour BF; Barley Flour Fen; Fenugreek Flour Soy; Soybean flour

L.S.D. blends; 0.5077

L.S.D. interaction; 0.8794

Orthogonal comparisons between levels of barley flour substitution over pulse flours were presented in Table 8. Wheat flour blends substituted with $10 \%$ barley flour had significantly higher 0.493 (Misr2), 0.668 (Giza171) and 0.550 (Gimmeza11) dry gluten percentage over blends that substituted with $20 \%$ barley flour. Also, blends that contained $20 \%$ barley flour showed insignificantly $0.094 \%$ higher dry gluten (Mirs2), $-0.677 \%$ dry gluten (Giza171) and $-0.120 \%$ dry gluten (Gimmeza11). In other words, increasing the level of barley flour substitution from 10 to $20 \%$ was associated with reduction in dry gluten percentage, while, increasing the substitution level from 20 to $30 \%$ barley flour was associated with an increase in dry gluten percentage. 
Table 8: Orthogonal comparisons between different levels of barley flour substitution to wheat flour reflected on dry gluten of flour blends.

\begin{tabular}{|l|c|c|c|c|c|c|}
\hline \multirow{2}{*}{ Comparisons } & \multicolumn{7}{|c|}{ Wheat cultivar } \\
\cline { 2 - 7 } & \multicolumn{2}{|c|}{ Misr2 } & \multicolumn{2}{c|}{ Giza171 } & \multicolumn{2}{c|}{ Gimmeza11 } \\
\cline { 2 - 7 } & Effect & Significance & Effect & Significance & Effect & Significance \\
\hline $\begin{array}{l}\text { WF+10\%BF v.s } \\
\text { WF+ 20\%BF }\end{array}$ & 0.493 & 0.000 & 0.668 & 0.002 & 0.550 & 0.000 \\
\hline $\begin{array}{l}\text { WF+20\%BF v.s } \\
\text { WF+ 30\%BF }\end{array}$ & -0.094 & 0.141 & -0.677 & 0.002 & -0.120 & 0.000 \\
\hline
\end{tabular}

WF; Wheat Flour BF; Barley FlourFen; Fenugreek FlourSoy; Soybean flour

\section{Role of cereals substitution}

Orthogonal comparisons between wheat/cereals blends were presented in Table 9.Substitution of wheat flour by rice flour in blends resulted in significant decrease in dry gluten percentage of Misr2 cultivar reached $0.056 \%$ over blends with sorghum flour. While, blends of Giza171 had significantly $0.233 \%$ higher dry gluten. Also, rice/Gimmeza11 flour blends showed insignificantly $0.010 \%$ higher dry gluten percentage relative to blends with sorghum flour.

Also, wheat blends with rice flour in comparison to blends with barley flour, indicated an increase in dry gluten percentage reached -0.027 $(\mathrm{p} \geq 0.561),-0.332(\mathrm{p} \geq 0.008)$ and $-0.227(\mathrm{p} \geq 0.0001)$ for wheat cultivars Misr2, Giza171 and Gimmeza11, respectively.

Table 9: Orthogonal comparisons for the effect of local cereals flour supplementation on dry gluten of flour blend

\begin{tabular}{|l|c|c|c|c|c|c|}
\hline \multirow{2}{*}{ Comparisons } & \multicolumn{6}{|c|}{ Wheat cultivar } \\
\cline { 2 - 7 } & \multicolumn{2}{|c|}{ Misr2 } & \multicolumn{2}{c|}{ Giza171 } & \multicolumn{2}{c|}{ Gimmeza11 } \\
\cline { 2 - 7 } & Effect & Significance & Effect & Significance & Effect & Significance \\
\hline WF+RF v.s WF+SF & 0.056 & 0.132 & -0.233 & 0.058 & -0.010 & 0.317 \\
\hline WF+ RF v.s WF+BF & -0.027 & 0.561 & -0.332 & 0.008 & -0.227 & 0.000 \\
\hline
\end{tabular}

WF; Wheat Flour BF; Barley FlourFen; Fenugreek FlourSoy; Soybean flour

\section{Role of pulse flour substitution:}

To illustrate the role of pulse flour substitution to dry gluten percentage of the studied flour blends, orthogonal comparisons were illustrated in Table 10. Fenugreek flour substitution to wheat flour in blends of Misr2 cultivar, gave unclear effect, while, caused significant increase of $-0.437 \%$ in Giza171 cultivar and a significant raise of $0.147 \%$ to dry gluten percentage of Gimmeza11 cultivar. A blend contained substitution with 5\% fenugreek flour and 5\% soybean flour contained significantly high $0.078,0.251$ and
$0.084 \%$ dry gluten in comparison to blends that contained a substitution of 5\% fenugreek for cultivars, Misr2, Giza171 and Gimmeza11, respectively. Also, the comparison between the group of blends that contained fenugreek and soybean flours versus those contained soybean flour revealed significant increase in dry gluten percentage due to the substitution by two pulse flour rather than soybean flour reached $0.078,-0.0172$ and $-0.111 \%$ for Misr2, Giza171 and Gimmeza11 cultivars, respectively.

Table 10: Orthogonal comparison for the effect of pulse flours supplementation to wheat / local cereals flours on dry gluten of flour blends

\begin{tabular}{|l|c|c|c|c|c|c|}
\hline \multirow{2}{*}{ Comparisons } & \multicolumn{9}{|c|}{ Wheat cultivar } \\
\cline { 2 - 7 } & \multicolumn{2}{|c|}{ Misr2 } & \multicolumn{2}{c|}{ Giza171 } & \multicolumn{2}{c|}{ Gimmeza11 } \\
\cline { 2 - 7 } & Effect & Significance & Effect & Significance & Effect & Significance \\
\hline $\begin{array}{l}\text { WF+(RF, SF,BF) + Fenv.s } \\
\text { WF+(RF, SF,BF) + SO }\end{array}$ & 0.000 & 0.000 & -0.437 & 0.000 & 0.147 & 0.000 \\
\hline WF+ Fen+ SOv.s WF+ Fen & -0.078 & 0.000 & -0.251 & 0.000 & -0.084 & 0.000 \\
\hline WF+ Fen+ SOv.s WF+ SO & -0.078 & 0.000 & -0.172 & 0.001 & -0.111 & 0.000 \\
\hline
\end{tabular}

WF; Wheat Flour RF; Rice flour Fen; Fenugreek Flour Soy; Soybean flour 
The recent finding match true with those reported by Abdelghafor et. al, 2013; Hadnadev et. al, 2011; Indrani et.al, 2013; Kasaye and Jha, 2015; Lin et.al, 2012; Maiya et.al, 2013 and Maria et.al, 2017.

Sollars and Rubenthaler (1971), reported the role of starch in three soft wheat flour tests studied through the use of reconstituted flours. Rice starch gave very poor cakes and cookies and low viscosities. These results indicate that starch must have certain physical and chemical properties for satisfactory performance.

Abdelghafor et al. (2013), investigated the chemical and rheological properties of different blends prepared using hard white winter wheat and whole or decorticated sorghum. They indicated that, Farinogram properties such as dough water absorption, development time and stability and Farinograph quality number decreased as the amount of substituted sorghum increased, whereas, mixing tolerance index increased. Moreover, at fixed gluten levels, as sorghum flour increased in the blend, wet gluten, dry gluten and gluten index decreased.Amir et al. (2015), investigated rheological properties of composite flours prepared by using whole wheat flour (Triticum aestivum), whole maize flour (Zea mays) and whole sorghum flour (Sorghum bicolor). Seven blends were prepared by homogenously mixing maize and sorghum flours with wheat flour in the percentage proportions: 0:100, 10:90, 20:80, 30:70, 15:15:70 (MF: WWF, SF: WWF and MF: SF: WWF) and later used to make cookies. They found that, Farinogram properties such as dough water absorption, dough development time (DDT), departure time and stability decreased as the amount of substituted sorghum and maize increased, whereas, arrival time increased. Sibanda et al. (2015) studied the effect of partial substitution of wheat flour with white grain sorghum flour on the rheological properties of the composites. Composite flours containing 10\%, 20\% and 30\% sorghum were used. Farinograph analysis showed a reduction in the water absorption of the composite dough as a result of sorghum addition with consequent longer development times and reduced dough stability. Dough development time increased from 4.3 minutes for the control to 14 minutes with sorghum replacement of at least $20 \%$ with a consequent decrease in stability from 12.27 minutes to 8.13 minutes. Sorghum substitution in excess of $10 \%$ had the effect of producing cohesive dough with higher tenacity and reduced elasticity. At 30\% sorghum addition, there was a complete loss of dough elasticity.

Niffenegger (1964) showed that, the starch and proteins of barley and wheat flour behave differently. The starch of barley flour has less thickening capacity and less water absorption than wheat. The protein has less gluten-like strength. Baked products which are dependent on glutenlike strength are made less successfully from barley flour than from wheat flour. Sollars and Rubenthaler (1971), reported the role of starch in three soft wheat flour tests studied through the use of reconstituted flours. They showed that, reconstituted flour with barley starch proved very good for cakes and cookies ad had viscosities close to this of flour with wheat starch.These results indicate that starch must have certain physical and chemical properties for satisfactory performance.

\section{Falling number}

Falling number is based on the ability of amylase to liquefy a starch gel. The activity of the enzyme is measured by determining the time in seconds required stirring and allowing stirrer to fall a measured distance through a hot aqueous flour or meal gel undergoing liquefaction. The lower the value of falling number the higher the diastatic activity and Vice versa (Schiller 1984).

The effect of rice flour and pulse flours replacement to wheat flour on falling number were presented in Table (11). Over the studied wheat cultivars, rice flour replacement at $10 \%$ of wheat flower showed significantly lower falling number (377.0 and 370.1 seconds for wheat flour and wheat flour $+10 \%$ rice flour blend, respectively) increasing the level of wheat flour replacement by $30 \%$ rice flour was significantly associated with an increase in falling number (387.6 Sec). Additional substitution by any of fenugreek or soybean flour at any of the studied rice flour substitution levels, gave significant decrease in falling number which indicate lower level of amylase activity.

As for the interaction between the studied wheat cultivars and the proposed blends, Misr2 blends showed significantly high figures of falling number proposing either low rate of diastolic activity or to the nature of starch granules and granule fragments, together with colloidal and molecularly dispersed starch molecules (Adegoke et al 2015). While, the least figures were presented by the wheat cultivar Giza 171. In the meantime, Gimmeza11 cultivar exhibited intermediate values.

In Misr2 wheat flour, falling number remained insignificantly different with $10 \%$ or $30 \%$ replacement with rice flour. Additional substitution with 5\% fenugreek flour gave significantly the lowest value of falling number (334.9) and $390.5 \mathrm{sec}$. for 10 and $30 \%$ replacement with rice flour). In Giza 171 wheat flour, $10 \%$ replacement with rice flour was associated with reduction in falling number, while, 30\% substitution with rice flour was associated with significant increase in falling number (365.2 Sec.). Gimmeza11 flour replaced by $10 \%$ rice flour, showed significant- 
ly lower falling number. Additional substitution by $5 \%$ fenugreek or soybean flour gave significantly similar and lower falling number. $30 \%$ replacement with rice flour gave significant rice in falling number $(387.2 \mathrm{sec})$.

Table 11: Effect of rice flour and pulses Flour substitution on falling number of flour lends of wheat cultivars

\begin{tabular}{|l|c|c|c|c|}
\hline \multirow{2}{*}{ Flour blends } & \multicolumn{4}{c|}{ Wheat cultivar } \\
\cline { 2 - 5 } & Misr2 & Giza171 & Gimmeza11 & Combined \\
\hline WF 100\% & 408.133 & 349.600 & 373.200 & 376.978 \\
\hline WF+ 10\% BF & 403.933 & 342.200 & 364.133 & 370.089 \\
\hline WF+10\% RF+ 5\% Fen & 334.933 & 338.367 & 361.267 & 344.856 \\
\hline WF+10\% RF+ 5\% Soy & 369.800 & 338.933 & 354.200 & 354.311 \\
\hline WF+ 20\% RF & 372.233 & 320.833 & 351.533 & 348.200 \\
\hline WF+ 20\% RF+ 5\% Fen & 347.467 & 311.667 & 332.167 & 330.433 \\
\hline WF+ 20\% RF+ 5\% Soy & 343.633 & 314.067 & 324.533 & 327.411 \\
\hline WF+ 30\% RF & 410.567 & 365.167 & 387.167 & 387.633 \\
\hline WF+ 30\% RF+ 5\% Fen & 390.533 & 351.833 & 365.833 & 369.400 \\
\hline WF+ 30\% RF+ 5\% Soy & 386.667 & 351.667 & 363.167 & 367.167 \\
\hline
\end{tabular}

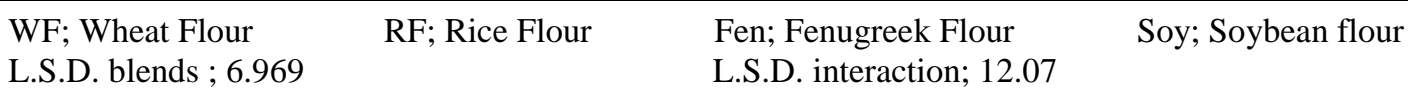

Orthogonal comparisons between different levels of rice flour replacement to wheat flour was presented in Table (12). Falling number figures of wheat flour $+10 \%$ rice flour blend significantly surpassed the corresponding values obtained for wheat flour + $20 \%$ rice flour blend by $7.556(\mathrm{P} \geq 0.00) 12.16(\mathrm{P} \geq$ 0.0001 ) and $11.89 \mathrm{sec}$ for wheat cultivars Misr2, Giza171 and Gimmeza11 respectively. Meanwhile, flour blends that included $30 \%$ rice flour, showed higher value of falling number overreached -20.74 $(\mathrm{P} \geq 0.0001),-20.35(\mathrm{P} \geq 0.0001)$ and $-17.99(\mathrm{P} \geq$ 0.0001) sec for Misr2, Giza171 and Gimmeza11 wheat flours, respectively.

Commonly, replacing wheat flour by 10 or $30 \%$ rice flours were associated with significant reduction in falling number. Additional substitution by pulse flour (fenugreek or soybean gave additional reduction in falling number. This might indicate a rise in amylase (diastatic) activity.

Effect of sorghum flour replacement to wheat flour and pulses flour substitution on falling number were presented in Table (13). Over the three studied wheat cultivars, substituting wheat flour by $10 \%$ sorghum flour gave significant rise to falling number (390.0 and 377.0 Sec for wheat/10\% sorghum flour blend and wheat flour, respectively). Meanwhile, additional replacement by $5 \%$ fenugreek or soybean flour significantly reduced falling number to equalize that of wheat flour. Also, $30 \%$ sorghum flour replacement to wheat flour gave additional significant falling number value (418.3 Sec.). Replacing another $5 \%$ by fenugreek or soybean flour gave substantial reduction in falling number (408.0 and 401.6 Sec for blends of $30 \%$ sorghum flour $+5 \%$ fenugreek flour and $30 \%$ sorghum flour $+5 \%$ soybean flour, respectively.

The interaction between wheat cultivar and blends illustrated that Misr2 flour and flour blends enjoyed significantly the highest figures of falling number relative to the other two wheat cultivars. The highest significant figures of falling number provided by wheat flour of Misr2 substituted by $30 \%$ sorghum flour (437.9 Sec.). Whereas, the least significant figure presented by Giza171 wheat flour replaced by $10 \%$ sorghum flour $+5 \%$ fenugreek or soybean flour (347.5 or $350.4 \mathrm{Sec}$, respectively).

Orthogonal comparisons between wheat flour blends with variable flour replacement were presented in Table (14). Blends with $10 \%$ sorghum flour replacement showed lower value of falling number reached16.68 $(\mathrm{P} \geq 0.0001), 6.883 \quad(\mathrm{P} \geq$ 0.0001 ) and 10.22 Sec for Misr2, Giza171 and Gimmeza11 cultivars over the corresponding blends of $20 \%$ sorghum flour. Also, blends with $30 \%$ sorghum flour replacement, had significantly higher values of falling number over those $20 \%$ sorghum flour reached 21.18, 31.81 and 23.77 Sec for cultivars Misr2, Giza171 and Gimmeza11, respectively.

Commonly, Misr2 flour and flour blends enjoyed the highest values of falling number, while, Giza171 gave opposite results. Replacing wheat flour by $10 \%$ or $30 \%$ rice flour was associated with significant rise in values of falling number. Also, pulse flour replacement to wheat flour reduced the values of falling number. 
Table 12: Orthogonal comparisons between different levels of rice flour substitution to wheat flour reflected on falling number of the flour blend

\begin{tabular}{|l|c|c|c|c|c|c|}
\hline \multirow{2}{*}{ Comparisons } & \multicolumn{5}{c|}{ Wheat cultivar } \\
\cline { 2 - 7 } & \multicolumn{2}{|c|}{ Misr2 } & \multicolumn{2}{c|}{ Giza171 } & \multicolumn{2}{c|}{ Gimmeza11 } \\
\cline { 2 - 7 } & Effect & Significance & Effect & Significance & Effect & Significance \\
\hline $\begin{array}{l}\text { WF+ 10\% RF v.s } \\
\text { WF+20\% RF }\end{array}$ & 7.556 & 0.003 & 12.156 & 0.000 & 11.894 & 0.000 \\
\hline $\begin{array}{l}\text { WF+ 20\% RF v.s } \\
\text { WF+30\%RF }\end{array}$ & -20.739 & 0.000 & -20.350 & 0.000 & -17.989 & 0.000 \\
\hline
\end{tabular}

WF; Wheat Flour

RF; Rice Flour

Fen; Fenugreek Flour

Soy; Soybean flour

Table 13: Effect of sorghum flour and pulses Flour substitution on falling number of flour blends of wheat cultivars

\begin{tabular}{|l|c|c|c|c|}
\hline \multirow{2}{*}{ Flour blends } & \multicolumn{4}{|c|}{ Wheat cultivar } \\
\cline { 2 - 5 } & Misr2 & Giza171 & Gimmeza11 & Combined \\
\hline WF 100\% & 408.133 & 349.600 & 373.200 & 376.978 \\
\hline WF+ 10\% SF & 420.600 & 365.367 & 384.167 & 390.044 \\
\hline WF+10\% SF+ 5\% Fen & 420.267 & 347.533 & 369.533 & 379.111 \\
\hline WF+10\% SF+ 5\% Soy & 400.233 & 350.400 & 367.833 & 372.822 \\
\hline WF+ 20\% SF & 392.500 & 342.433 & 360.533 & 365.156 \\
\hline WF+ 20\% SF+ 5\% Fen & 379.900 & 346.067 & 349.667 & 358.544 \\
\hline WF+ 20\% SF+ 5\% Soy & 368.633 & 333.500 & 350.033 & 350.722 \\
\hline WF+ 30\% SF & 437.933 & 408.800 & 408.167 & 418.300 \\
\hline WF+ 30\% SF+ 5\% Fen & 416.667 & 409.200 & 398.133 & 408.000 \\
\hline WF+ 30\% SF+ 5\% Soy & 413.533 & 394.833 & 396.533 & 401.633 \\
\hline
\end{tabular}

WF; Wheat Flour SF; Sorghum Flour

L.S.D. blends ; 6.969

L.S.D. interaction; 12.07

Table 14: Orthogonal comparisons between different levels of sorghum flour substitution to wheat flour reflected on falling number of the flour blend

\begin{tabular}{|c|c|c|c|c|c|c|}
\hline \multirow{3}{*}{ Comparisons } & \multicolumn{6}{|c|}{ Wheat cultivar } \\
\hline & \multicolumn{2}{|c|}{ Misr 2} & \multicolumn{2}{|c|}{ Giza171 } & \multicolumn{2}{|c|}{ Gimmeza11 } \\
\hline & Effect & Significance & Effect & Significance & Effect & Significance \\
\hline $\begin{array}{l}\mathrm{WF}+10 \% \mathrm{SF} v . s \\
\mathrm{WF}+20 \% \mathrm{RF}\end{array}$ & 16.678 & 0.000 & 6.883 & 0.000 & 10.217 & 0.000 \\
\hline $\begin{array}{l}\mathrm{WF}+20 \% \mathrm{SF} v \cdot s \\
\mathrm{WF}+30 \% \mathrm{RF}\end{array}$ & -21.183 & 0.000 & -31.806 & 0.000 & -23.767 & 0.000 \\
\hline
\end{tabular}

\section{WF; Wheat Flour SF; Sorghum Flour}

\section{Barley flour replacement}

(Table 15) showed falling number of wheat flour and wheat flour blends for the studied wheat cultivars. Over the studied wheat cultivars, replacing wheat flour by $10 \%$ barley flour had not affected the value of falling number. Addition replacement by $5 \%$ fenugreek or soybean flour significantly reduced falling number 362.9 and $358.3 \mathrm{Sec}$ for $30 \%$ barley flour + fenugreek and $30 \%$ barley flour + soybean flour re-
Fen; Fenugreek Flour

Soy; Soybean flour

spectively. Further significant reduction in falling number was obtained when the level of wheat flour replacement reached $30 \%$ barley flour (355.9Sec.). Replacing 5\% fenugreek flour $+30 \%$ barley flour to wheat flour gave significantly higher falling number. But, blend of wheat flour $+30 \%$ barley flour $+5 \%$ soybean flour had significantly lower falling number (347.2 Sec). 
The significant interaction between wheat cultivars and blends was mainly due to variable magnitude of falling number figures among the studied cultivars. Since, Misr2 gave significantly higher values, corresponded by lower magnitude value provided by Gimmeza11 cultivar. The highest falling number value were these of Misr2 wheat flour and wheat flour + $10 \%$ barley flour (408.1 and 398.6 Sec., respectively). While the last significant values were these of Gimmeza11 wheat flour $+10 \%$ barley flour $+5 \%$ soybean flour or Gimmeza11 wheat flour $+30 \%$ barley flour (342.2 and $342.8 \mathrm{Sec}$., respectively).

Table 15: Effect of barley flour and pulses Flour substitution on falling number of flour blends of wheat cultivars

\begin{tabular}{|l|c|c|c|c|}
\hline \multirow{2}{*}{ Flour blends } & \multicolumn{4}{|c|}{ Wheat cultivar } \\
\cline { 2 - 5 } & Misr2 & Giza171 & Gimmeza11 & Combined \\
\hline WF $100 \%$ & 408.133 & 349.600 & 373.200 & 376.978 \\
\hline WF+ 10\% BF & 398.633 & 369.500 & 362.500 & 376.878 \\
\hline WF+10\% BF+ 5\% Fen & 375.233 & 361.500 & 352.200 & 362.978 \\
\hline WF+10\% BF+ 5\% Soy & 370.233 & 362.467 & 342.167 & 358.289 \\
\hline WF+ 20\% BF & 349.100 & 324.467 & 319.867 & 331.144 \\
\hline WF+ 20\% BF+ 5\% Fen & 337.567 & 325.200 & 329.000 & 330.589 \\
\hline WF+ 20\% BF+ 5\% Soy & 327.400 & 324.733 & 311.633 & 321.256 \\
\hline WF+ 30\% BF & 365.000 & 359.800 & 342.833 & 355.878 \\
\hline WF+ 30\% BF+ 5\% Fen & 370.500 & 366.500 & 371.567 & 369.522 \\
\hline WF+ 30\% BF+ 5\% Soy & 348.700 & 347.833 & 344.967 & 347.167 \\
\hline
\end{tabular}

WF; Wheat Flour BF; Barley Flour

Orthogonal comparisons between blends of different levels of barley flour replacement were presented in Table (16). Blends with $10 \%$ barley flour had lower values of falling number over these containing $20 \%$ barley flour by $21.67(\mathrm{P} \geq 0.0001), 19.84(\mathrm{P} \geq$ $0.0001)$, and $16.06(\mathrm{P} \geq 0.0001)$, Sec. for Misr2, Gi-
Fen; Fenugreek Flour

Soy; Soybean flour

za171 and Gimmeza17, respectively. In the meantime, blends with $30 \%$ barley flour replacement had higher falling number relative to those contained $20 \%$ barley flour by11.69 ( $\mathrm{P} \geq 0.0001), 16.62(\mathrm{P} \geq 0.0001)$, and 16.48 seconds for Misr2, Giza171 and Gimmeza11, respectively.

Table 16: Orthogonal comparisons between different levels of barley flour substitution to wheat flour reflected on falling number of the flour blend

\begin{tabular}{|l|c|c|c|c|c|c|}
\hline \multirow{2}{*}{ Comparisons } & \multicolumn{4}{c|}{ Wheat cultivar } \\
\cline { 2 - 7 } & \multicolumn{2}{|c|}{ Misr2 } & \multicolumn{2}{c|}{ Giza171 } & \multicolumn{2}{c|}{ Gimmeza11 } \\
\cline { 2 - 7 } & Effect & Significance & Effect & Significance & Effect & Significance \\
\hline $\begin{array}{l}\text { WF+ 10\% RF v.s } \\
\text { WF+20\% RF }\end{array}$ & 21.672 & 0.000 & 19.844 & 0.000 & 16.061 & 0.000 \\
\hline $\begin{array}{l}\text { WF+ 20\% RF v.s } \\
\text { WF+30\%RF }\end{array}$ & -11.689 & 0.000 & -16.622 & 0.000 & -16.478 & 0.000 \\
\hline
\end{tabular}

\section{WF; Wheat Flour $\quad$ BF; Barley Flour}

\section{Role of cereals replacement}

Orthogonal comparisons between groups of blends containing different cereals were presented in Table (17). Wheat flour blends contained sorghum flour replacement gave higher figures of falling number reached $16.14,14.63$ and 10.33 in comparison to the corresponding blends with rice flour replacement for wheat flours of Misr2, Giza171 and Gimmeza11,
Fen; Fenugreek Flour Soy; Soybean flour respectively. Also Misr2 blends with rice flour gave lower falling number over blends with barley flour (6.522 Sec). While, Giza171 blends with rice flour had higher values of falling number in comparison to those blends with barley flour while, Gimmeza11 blends with rice flour had7.07 Sec. Rise in falling number in comparison to blends with barley flour. 
Table 17: Orthogonal comparisons for the effect of pulse flours substitution to wheat / local cereals flour on falling number of flour blend

\begin{tabular}{|c|c|c|c|c|c|c|}
\hline \multirow{3}{*}{ Comparisons } & \multicolumn{6}{|c|}{ Wheat cultivar } \\
\hline & \multicolumn{2}{|c|}{ Misr2 } & \multicolumn{2}{|c|}{ Giza171 } & \multicolumn{2}{|c|}{ Gimmeza11 } \\
\hline & Effect & Significance & Effect & Significance & Effect & Significance \\
\hline $\begin{array}{l}\mathrm{WF}+\mathrm{RF} v \cdot s \\
\mathrm{WF}+\mathrm{SF}\end{array}$ & -16.139 & 0.000 & -14.633 & 0.000 & -10.033 & 0.000 \\
\hline $\begin{array}{l}\mathrm{WF}+\mathrm{RF} v . s \\
\mathrm{WF}+\mathrm{BF}\end{array}$ & 6.522 & 0.000 & -5.959 & 0.000 & 7.070 & 0.000 \\
\hline
\end{tabular}

WF; Wheat Flour BF; Barley Flour

\section{Overall role of pulse flour replacement:}

Orthogonal comparisons between groups of flour blends contained different pulse flours were presented in Table (18). Blends included fenugreek flour showed lower values of falling number reached 2.285, 2.638 and $4.003 \mathrm{sec}$ for blends of Misr2, Giza171 and Gimmeza11, respectively. Comparison between blend that contained fenugreek and soybean flour replacement versus blends contained fenugreek flour replacement showed that inclusion of both pulse flours increase falling number by 0.753 (Misr2) and 0.539 (Giza171).
Fen; Fenugreek Flour Soy; Soybean flour

While, showed $1.758 \mathrm{sec}$ raise in falling number of Gimmeza11 blends. Also, the differences between wheat flour blends that included replacement by both pulse flour types and the corresponding blends with soybean flour, showed that fenugreek flour replacement was associated with increase in falling number reached 1.168 and 1.019 seconds for Misr2 and Giza171 wheat cultivar blends, respectively. While, Gimmeza11 wheat flour blends showed that fenugreek flour replacement raised falling number by $1.030 \mathrm{sec}-$ onds.

Table 18: Orthogonal comparison for the effect of pulse flours supplementation to wheat/ local cereals flours on falling number of flour blend

\begin{tabular}{|l|l|l|l|l|l|l|}
\hline \multirow{2}{*}{ Comparisons } & \multicolumn{7}{|c|}{ Wheat cultivar } \\
\cline { 2 - 7 } & \multicolumn{2}{|c|}{ Misr 2 } & \multicolumn{2}{c|}{ Giza 171 } & \multicolumn{2}{c|}{ Gimmeza 11 } \\
\cline { 2 - 7 } & Effect & Significance & Effect & Significance & Effect & Significance \\
\hline $\begin{array}{l}\text { WF+(RF, SF,BF)+ Fen v.s } \\
\text { WF+(RF, SF,BF)+ SO }\end{array}$ & 2.285 & 0.092 & 2.638 & 0.000 & 4.003 & 0.000 \\
\hline $\begin{array}{l}\text { WF+ Fen+ SO v.s } \\
\text { WF+ Fen }\end{array}$ & -0.753 & 0.191 & -0.539 & 0.041 & 1.758 & 0.000 \\
\hline $\begin{array}{l}\text { WF+ Fen+ SO v.s } \\
\text { WF+ SO }\end{array}$ & -1.168 & 0,044 & -1.019 & 0.000 & 1.030 & 0.003 \\
\hline
\end{tabular}

WF; Wheat Flour RF; Rice Flour

Dhingar and Jood (2002), studied the physicochemical and nutritional properties of cereal pulse blends for bread making. Supplementation of soy (full fat and defatted) and barley flours to wheat flour at 51 10,15 and $20 \%$ levels were studied. They found that, the gluten content and sedimentation value of flour blends decreased and water absorption capacity increased with increase in the level of soybean and barley flour separately and in combinations to bread flour. Hruskova et al. (2003), studied the improved effect of malt flour on the rheological properties of full dough system during the proofing, the oven spring and the baking process. The influence of small amounts of malt flour on the proofing stability was significant. The increase was about $40 \%$ for both sets of flour. The proofing time was not prolonged as significantly as the dough elasticity in all samples.

\section{BF; Barley Flour}

SF; Sorghum Flour

Dhingra and Jood (2004), indicated that, the gluten content, sedimentation value and water absorption capacity of the flour blends and the mixing time of the dough decreased with increase in the level of soybean and barley flour separately and in combinations. Protein and glutelin contents increased significantly on blending of soy flour (full-fat and defatted) to bread wheat flour. Lin et al. (2012) illustrated the effect of barley on the mechanical properties of wheat flour dough, which was important for determining both the properties of the dough during processing and the quality of the end-product. They found that, increasing levels of barley flour correspondingly decreased the gluten content and increased the $\beta$-glucan content. Upon incorporation of barley flour, the dough development time, departure time and stability time are decreased, but, the mixing tolerance index is in- 
creased. The incorporation of barley flour into wheat flour also significantly decreased the extensibility, increased the value of $\mathrm{R} / \mathrm{E}$ ratio and decreased the value of work input. Hussein et al. (2013), focused on substituting a part of wheat flour (WF) with whole meal barley (WBF), gelatinized corn flour (GCF) and both of them in balady bread. Blending WBF or GCF with WF gave higher rheological parameters of dough. Hussein et al. (2013),concluded that, wheat flour could be replaced with whole barely flour and gelatinized corn flour at the level of $30: 15 \%$ without drastic effect on the technological quality. Moreover, higher nutritive values of this bread were achieved.Maiya et al. (2013), demonstrates that, parotta enriched with dietary fibre and $\beta$-glucan can be prepared by partially substituting wheat flour with barley flour (BF). In general, use of BF up to $40 \%$ significantly increased dough strength, extensibility and parotta-making characteristics of wheat flour. Abou- Raya et al. (2014), studied the effect of adding barley flour by $10,15,20 \%$, oat flour $10,15,20 \%$ and the two together by $10+10,15+15$, and $20+20 \%$ on the rheological characteristics of the dough. They reached that, adding barley at different rates led to increasing the rate of water absorption, duration of kneading dough, consistently for maximum strength and the weakness of dough. Also, adding oats, at different rates led to low rate of water absorption, while, increased the access time, the stability of the dough and the dough weakness. In the case of mixing the two together, the results obtained through farinograph showed that, barley and oat together in different proportions led to the low rate of water absorption, while the arrival time, dough development, the dough stability and dough weakness were determined. Also, they said that, the best ratio of barley addition was $15 \%$ and for oats was $10 \%$. Whereas, in case of mixed barley and oats, the best ratio was $15 \%$.Tulse et al. (2014) carried out a study on the co-milled straight run flours obtained by varying proportions of wheat, barley and green gram. Mixing ratios were; (90:5:5), $(80: 10: 10)$ and $(70: 15: 15)$. As the amount of GG and $\mathrm{BR}$ increased in blend, water absorption increased (56.6-58.4\%) and dough stability and extensibility values decreased (104-92 mm).

\section{CONCLUSION}

Wheat blends with rice flour in comparison to blends with barley flour, indicated a reduction in dry gluten percentage reached $-0.027(\mathrm{p} \geq 0.561),-0.332$ $(p \geq 0.008)$ and $-0.227(p \geq 0.0001)$ for wheat cultivars Misr2, Giza171 and Gimmeza11, respectively. A blend contained substitution with $5 \%$ fenugreek flour and 5\% soybean flour contained significantly less $0.078,0.251$ and $0.084 \%$ dry gluten in comparison to blends that contained a substitution of 5\% fenugreek for cultivars, Misr2, Giza171 and Gimmeza11, respectively. Also, the comparison between the group of blends that contained fenugreek and soybean flours versus those contained soybean flour revealed significant reduction in dry gluten percentage due to the substitution by two pulse flour rather than soybean flour reached $-0.078,-0.0172$ and $-0.111 \%$ for Misr2, Giza171 and Gimmeza11 cultivars, respectively.

Substitution of wheat flour by rice flour in blends resulted in significant decrease in dry gluten percentage of Misr2 cultivar reached $0.056 \%$ over blends with sorghum flour. While, blends of Giza171 had significantly $0.233 \%$ higher dry gluten. Also, rice/Gimmeza11 flour blends showed insignificantly $0.010 \%$ higher dry gluten percentage relative to blends with sorghum flour.

Also, wheat blends with rice flour in comparison to blends with barley flour, indicated an increase in dry gluten percentage reached $-0.027 \quad(\mathrm{p} \geq 0.561), \quad-0.332$ $(p \geq 0.008)$ and $-0.227(p \geq 0.0001)$ for wheat cultivars Misr2, Giza171 and Gimmeza11, respectively.

Wheat flour blends contained sorghum flour replacement gave higher figures of falling number reached $16.14,14.63$ and 10.33 in comparison to the corresponding blends with rice flour replacement for wheat flours of Misr2, Giza171 and Gimmeza11, respectively. Also Misr2 blends with rice flour gave lower falling number over blends with barley flour (6.522 Sec). While, Giza171 blends with rice flour had higher values of falling number in comparison to those blends with barley flour while, Gimmeza11 blends with rice flour had7.07 Sec. Rise in falling number in comparison to blends with barley flour.

Blends included fenugreek flour showed lower values of falling number reached 2.285, 2.638 and $4.003 \mathrm{sec}$ for blends of Misr2, Giza171 and Gimmeza11, respectively. Comparison between blend that contained fenugreek and soybean flour replacement versus blends contained fenugreek flour replacement showed that inclusion of both pulse flours increase falling number by 0.753 (Misr2) and 0.539 (Giza171). While, showed $1.758 \mathrm{sec}$ raise in falling number of Gimmeza11 blends. Also, the differences between wheat flour blends that included replacement by both pulse flour types and the corresponding blends with soybean flour, showed that fenugreek flour replacement was associated with increase in falling number reached 1.168 and 1.019 seconds for Misr2 and Giza171 wheat cultivar blends, respectively. While, Gimmeza11 wheat flour blends showed that fenugreek flour replacement raised falling number by $1.030 \mathrm{sec}-$ onds.

\section{REFERENCES}

Abdelghafor, R.F., A.I. Mustafa, A.M.H. Ibrahim, Y.R. Chen and P.G. Krishnan (2013). Effects of sorghum flour addition on chemical and rheological properties of hard white winter wheat. Advance Journal of Food Science and Technology, 5(11): 1407-1412. 
Abou- Raya, M. A., M. M. Rabiae, A.S. El - Shazly and E.S.E- Fadaly (2014). Effect of adding barley and oat flour on the rheological propertie of bread dough. J. Food and Dairy Sci., Mansoura Univ., 5 (8): 641 - 652.

Amir, B., G. Mueen-ud-din, M. Abrar, S. Mahmood, M. Nadeem and A. Mehmood (2015). Chemical composition, rheological properties and cookies making ability of composite flours from maize, sorghum and wheat. Journal of Agroalimentary Processes and Technologies, 21(1), 28-35.

Bhatt, S.M. and R.K. Gupta (2015). Bread (composite flour) formulation and study of its nutritive, phytochemical and functional properties. Journal of Pharmacognosy and Phytochemistry; 4(2): 254268.

Dhingar, S. and S. Jood (2002). Physico-chemical and nutritional properties of cereal- pulse blends for bread making. Nutrition and Health, 16:183194.

Dhingra S. and S. Jood (2004). Effect of flour blending on functional, baking and organoleptic characteristics of bread. International Journal of Food Science and Technology, 39:213-222.

Elisa Julianti, HerlaRusmarilin, Ridwansyah and Era Yusraini (2017). Functional and rheological properties of composite flour from sweet potato, maize, soybean and xanthan gum. Journal of the Saudi Society of Agricultural Sciences, 16: 171-177

Hadnađev, T.D., A. Torbica and M. Hadnađev (2011). Rheological properties of wheat flour substitutes/alternative crops assessed by Mixolab. Procedia Food Sci., 1: 328- 334.

Harinder, K., B. Kaur and S. Sharma (1999). Studies on the baking properties of wheat: Pigeonpea flour blends. Plant Foods for Human Nutrition, 54: 217-226.

Hruskova, M., I. Svec and I. Kucerova (2003). Effect of malt flour addition on the rheological properties of wheat fermented dough. Czech J. Food Sci., 21(6): 210-218.

Hussein, A.M.S., M.M. Kamil, Nefisa A. Hegazy, S.A.H. Abo El-Nor (2013). Effect of Wheat Flour Supplemented with Barely and/or Corn Flour on Balady Bread Quality. Pol. J. Food Nutr. Sci., 63(1): 11-18.

Indrani, D., P.Swetha, C.Soumya, J. Rajiv and G.V. Rao (2011).Effect of multigrains on rheological, microstructural and quality characteristics of north Indian parotta -
An Indian flat bread. Food Science and Technology, 44 (3):719-724.

Lin, S.Y., H.H. Chen, S. Lu and P.C. Wang (2012). Effects of blendings of wheat flour with barely flour on dough and steamed bread properties. JournalofTextureStudies43:438- 444.

Maiya, G.K., B.G. Shwetha and D. Indrani. (2013). Effect of barley flour on rheological characteristics of dough, organoleptic, nutritional and storage characteristics of south Indian parotta. Food Science and Technology International, 21(1): 24-32.

Maria, Dolores Alvarez, B. Herranz, R. Fuentes. F.J. Cuesta and W. Canet (2017). Replacement of wheat flour by chickpea flour in muffin batter: Effect on rheological properties. Journal of Food Process Engineering, 40: 1-13.

Miñarro, B., E. Albanell, N. Aguilar, B. Guamis and M. Capellas (2012). Effect of legume flours on baking characteristics of gluten-free bread. Journal of Cereal Science 56 : 476- 481.

Niffenegger, E.V. (1964), chemical and physical characteristics of barley flour as related to its use in baked products. A thesis submitted to the Graduate Faculty in partial fulfillment of the requirements for the degree of Master of Science in Home Economics, Montana State College Bozeman, Montana.

Popa, C.N., Radiana-Maria Tamba-Berehoiu, AnaMaria Hutan and S. Popescu (2014). The significance of some flour quality parameters as quality predictors of bread. Scientific Bulletin. Series F. Biotechnologies, XVIII: 135-140.

Qarooni, J.,R.A. Orth and M. Wootton (1987).A test baking technique for Arabic bread quality. Cereal Science Journal, 6: 69-80.

Różyło, R. and J. Laskowski (2011). Predicting Bread Quality (Bread Loaf Volume and Crumb Texture). Pol. J. Food Nutr. Sci., 61 (1):61-67.

Sibanda, T., T. Ncube and N. Ngoromani (2015). Rheological Properties and Bread Making Quality of White Grain Sorghum-Wheat Flour Composites. International Journal of Food Science and Nutrition Engineering, 5(4): 176-182.

Sollars, W.F. and G.L. Rubenthaler (1971). Performance of wheat and other starches in reconstituted flours. Wheat and Starches in Flours, 48: 397410.

Tulse, S.B., V. Reshma, J. Rajiv and S.D. Sakhare (2014). Effect of co-milled wheat, green gram and barley on the rheological and quality characteristics of cookies. Food Science and Technology International, 21(7): 492-502. 


\section{استبدال دقيق القـح بدقيق الحبوب و البقول المحليه كاسلوب للتفلب على مشكلة نقص الحبوب بمصر}

\section{r - المحتوى من الجلوتين و رقم السقوط}

\section{زينب رافت عطيه و مسعد عبد السيد الجنبيهى و محمد عبد الستار احمد}

خلطات دقيق القـح مع دقيق الأرز عند مقارنتها بالخلطات مع دقيق الثعير تظهر إنخفاض في نسبة



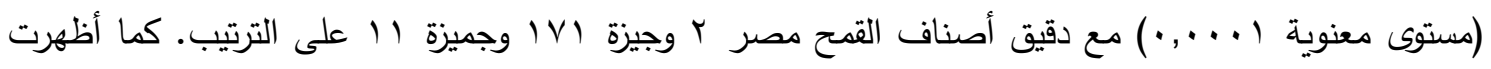
الخلطات المحتوية على إحلالات ه\% دقيق حلبة وه\% دقيق فول صويا على كميات أقل معنوية من الجلوتين

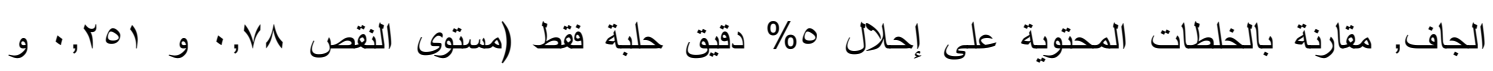

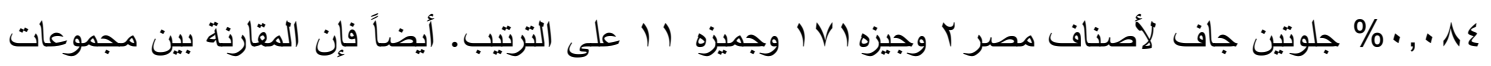

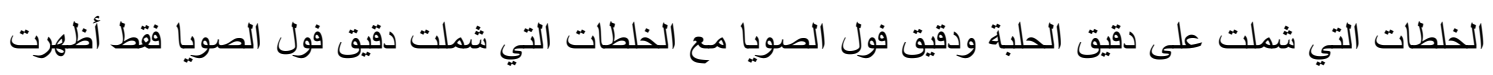
نقص معنوي في نسبة الجلوتين الجاف نتيجة للإحلال بكلا نوعي دقيق البقول بالمقارنة بالإحلال بدقيق فول

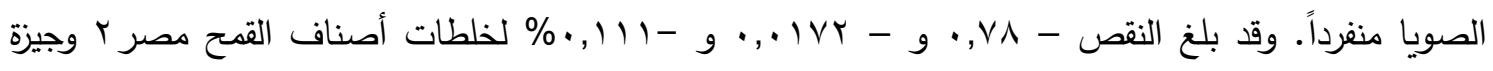

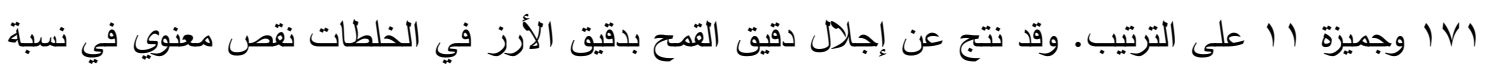

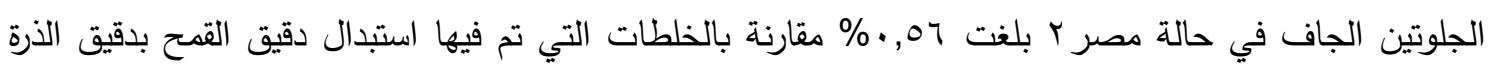

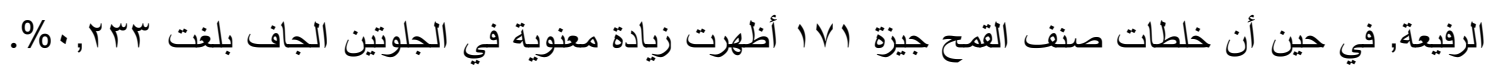





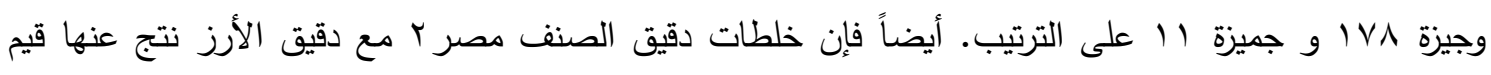

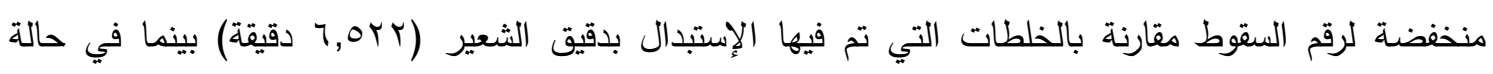
خلطات القدح جيزه IV مع الإستبدال بدقيق الأرز فقد أظهرت قيم مرتفعة لرقم السقوط مقارنة بالخلطات التي تم

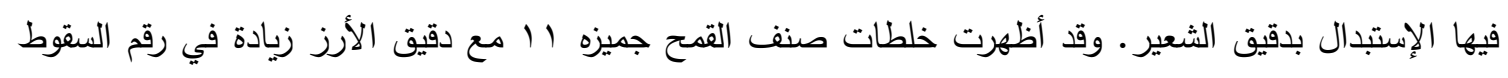

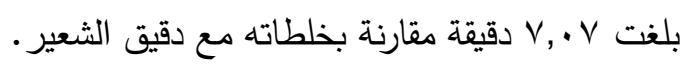


Vol. 65, No. 2, pp. 69-83, 2020

Alex. J. Agric. Sci. 